\title{
Simulation of Diurnal Rainfall Variability over the Maritime Continent with a High-Resolution Regional Climate Model
}

\author{
Bhuwan C. BHATT, Stefan SOBOLOWSKI \\ Uni Research Climate, Bergen, Norway \\ The Bjerknes Center for Climate Research, Bergen, Norway \\ and
}

\section{Atsushi HIGUCHI}

Center for Environmental Remote Sensing, Chiba University

(Manuscript received 3 November 2014, in final form 17 August 2015)

\begin{abstract}
The characteristics of diurnal precipitation variability are evaluated over the tropical Maritime Continent (MC) from both satellite observations and high-resolution simulations performed using the Weather Research and Forecasting (WRF) model.

Simulations using the Kain-Fritsch convective scheme showed a slight improvement in representing the precipitation diurnal cycle compared with those using the other two schemes examined here. The influence of boundary forcing was compared between the National Center for Environmental Prediction-Final Analysis (NCEP-FNL) and the Norwegian Earth System Model (NorESM). In these experiments, simulations with NCEP-FNL data as lateral boundary conditions outperformed those with NorESM boundary conditions. All WRF simulations exaggerated the amplitude of diurnal precipitation over the land. However, the WRF captured the principal shape of the observed diurnal cycle well. An empirical orthogonal function (EOF) analysis was applied and the first two modes from satellite data explained up to about $80 \%$ of the total diurnal variance. The results confirm that the land-sea breeze circulation plays a significant role in the diurnal cycle of precipitation. The radiatively induced land-sea breeze circulation and its timing were well reproduced in the WRF simulations. These results suggest that higher resolution simulations that reproduce heterogeneous local-scale processes are likely necessary in order to resolve diurnal variability of precipitation and its future changes over the MC.
\end{abstract}

Keywords downscaling; diurnal cycle of precipitation; maritime continent

\section{Introduction}

As interest in describing potential future changes in patterns of precipitation at ever finer spatial and temporal scales has increased, it has become critical

Corresponding author: Bhuwan C. Bhatt, Allegaten 55, NO-5007, Bergen, Norway

E-mail: bbh081@uni.no

(C)2015, Meteorological Society of Japan that the models capture precipitation features and their underlying mechanisms on sub-daily time scales. One such feature of precipitation is the diurnal cycle over tropical regions, which is characterized by the daily minimum and maximum precipitation intensities, their timing, their range, and the frequency of precipitation throughout the day. This cycle is important for a number of stakeholders including those in agriculture, water resources, and risk management. Typically, the 
diurnal cycle of precipitation is poorly represented in coarse-grained models (Dai and Trenberth 2004; Dai 2006). With data aggregated on daily or longer timescales (e.g., monthly, seasonal, and annual) these errors may be overlooked. However, in order to have confidence in modeled projections at the sub-daily scale, one must provide, at the very least, a demonstration that a particular modeling system is able to capture the relevant physical processes and thus reproduce the characteristics of the diurnal cycle of precipitation. The present study examines the ability of the Weather Research and Forecasting (WRF) modeling system to produce the diurnal cycle of precipitation, its variability, and its related local-scale circulation patterns over the tropical Maritime Continent (MC) in Southeast Asia. This research is motivated in part by the desire to increase confidence in future climate projections and better understand potential changes in this important feature of tropical climate. However, before evaluations on future projections can be conducted, the modeling tools must be first declared fit for purpose and the value-added determined.

The MC is a well-known heavy precipitation region (Philander 2008; Chang et al. 2005). The heavy precipitation is not only a local phenomenon but also affects the large-scale atmospheric circulation (Neale and Slingo 2003) and thus global climate. It is the surface inhomogeneity of the MC, due to the complex system of archipelagos and shallow seas, that gives rise to highly localized forcing of convective activity and precipitation (Yang and Slingo 2001). It is widely accepted that most of the precipitation over the MC is caused by local convective activity in synchronization with the diurnal cycle of precipitation (Hara et al. 2009; Kitoh and Arakawa 2005). Land-sea breezes (e.g., Mak and Walsh 1976; Joseph et al. 2008) are generated primarily by local thermal contrasts between land and sea surfaces. These local circulations converge over the land (sea) to produce daytime (nocturnal) precipitation.

The MC remains a region where global climate models struggle to realistically represent the spatial and temporal distribution of precipitation and its variability (Jourdain et al. 2013). For example, a number of studies evaluated the representation of the diurnal cycle in the general circulation model (GCM) using multiple observation datasets and found that the modeled diurnal cycle generally has a precipitation peak that is too early and too strong (Randall et al. 1991; Dai and Trenberth 2004; Dai 2006). Additional studies report shortcomings in the ability of GCMs to reproduce the phase and amplitude of the diurnal cycle of precipitation (Neale and Slingo 2003; Lee et al. 2007a,b; Dirmeyer et al. 2012). Most of these studies also raise the issue of the horizontal resolution and its role in the accurate representation of the diurnal cycle.

Relatively few studies over the MC have employed the regional climate model (RCM) (Zhou and Wang 2006; Wang et al. 2007; Koo and Hong 2010; Lee et al. 2007b). Zhou and Wang (2006) studied geographic effects and the offshore migration of the diurnal cycle of precipitation. Wang et al. (2007) investigated the effect of lateral convective entrainment-detrainment rates on a simulated diurnal cycle of precipitation. Koo and Hong (2010) investigated diurnal variability and showed that cumulus parameterization modulates the simulated timing of maximum precipitation over land. Qian (2008) simulated the diurnal precipitation cycle over Java, Indonesia and showed that the model was able to reproduce the diurnal cycle, but the simulation was restricted to a single island, and thus the results could not be extended to the rest of the region. Some researchers even conducted very high-resolution simulations $(7 \mathrm{~km})$ over the $\mathrm{MC}$ and found improvement in the simulation of the diurnal cycle of precipitation, but their results were drawn from a very short 1-month simulation (Sato et al. 2009).

In general, the literature points toward problems in the boundary layer and convective parameterizations (Wang et al. 2007; Koo and Hong 2010), inadequate grid resolution (Lee et al. 2007b), error in precipitation generation (Gianotti et al. 2012), and error in peak precipitation time as compared with the observations (Joseph et al. 2008). Most of these studies involved RCMs and did not make use of high-resolution datasets.

The current study builds on previous work by utilizing high-resolution simulations (10-25 km) over the MC. While it is expected that the $25 \mathrm{~km}$ resolution provides gross features of the diurnal cycle at mesoalpha scales, the $10 \mathrm{~km}$ resolution is needed to resolve meso-beta and the outer edge of the meso-gamma scale features (e.g., land-sea breezes and orographic enhancement). As the MC consists of a fragmented distribution of topographically complex islands and seas (land-water contrasts), these high horizontal resolutions are crucial and are expected to provide more accurate surface forcing of local to regional scale climate processes. The inadequate representation of land-sea gradients and topography in low-resolution climate model simulations over the MC is reported in earlier studies (Neale and Slingo 2003). 
Table 1. Descriptions of the datasets used.

\begin{tabular}{|c|c|c|}
\hline Data & Analysis Periods & Domain size (resolutions) \\
\hline \multicolumn{3}{|c|}{ Model/Boundary conditions: } \\
\hline $\begin{array}{l}\text { WRF/NCEP25 } \\
\text { (NCEP25) }\end{array}$ & $2000-2005$ & $\begin{array}{l}85 \mathrm{E}-155 \mathrm{E}, 11.8 \mathrm{~S}-11.8 \mathrm{~N} \\
(25 \mathrm{~km} \times 25 \mathrm{~km}, 3 \text { hourly })\end{array}$ \\
\hline $\begin{array}{l}\text { WRF/NCEP10 } \\
\text { (NCEP10) }\end{array}$ & 2004 & $\begin{array}{l}86 \mathrm{E}-125 \mathrm{E}, 11.8 \mathrm{~S}-11.8 \mathrm{~N} \\
(10 \mathrm{~km} \times 10 \mathrm{~km}, \text { hourly })\end{array}$ \\
\hline $\begin{array}{l}\text { WRF/NorESM } \\
\text { (NorESM/WRF) }\end{array}$ & 2004 & $\begin{array}{l}86 \mathrm{E}-125 \mathrm{E}, 11.8 \mathrm{~S}-11.8 \mathrm{~N} \\
(10 \mathrm{~km} \times 10 \mathrm{~km}, \text { hourly })\end{array}$ \\
\hline \multicolumn{3}{|l|}{ Observations: } \\
\hline TRMM3B42 & $2000-2005$ & $\begin{array}{l}85 \mathrm{E}-155 \mathrm{E}, 11.8 \mathrm{~S}-11.8 \mathrm{~N} \\
(25 \mathrm{~km} \times 25 \mathrm{~km}, 3 \text { hourly })\end{array}$ \\
\hline GSMap_MVK+ & 2004 & $\begin{array}{l}86 \mathrm{E}-125 \mathrm{E}, 11.8 \mathrm{~S}-11.8 \mathrm{~N} \\
(10 \mathrm{~km} \times 10 \mathrm{~km} \text {, hourly })\end{array}$ \\
\hline
\end{tabular}

The purposes of this paper are to analyze the performance of high-resolution WRF model simulations with respect to the diurnal cycle, compare the results with observations, and study the impact of model boundary forcing. We focus on the diurnal precipitation over the MC in the year 2004. From the perspective of large-scale climate variability, 2004 was a weak El-Nino year (http://www.ggweather.com/enso/ oni.htm), which makes it an ideal choice for study due to weak large-scale background state. The outline of this paper is as follows: In Section 2, we describe the data and methods. Section 3 provides results. Section 4 is devoted to the discussion and conclusions.

\section{Data and methods}

Table 1 shows the datasets used in this study. The model precipitation data are from the WRF model. WRF version 3.3.1 is employed here as a regional model with a focus predominantly on the precipitation output (Skamarock et al. 2008). A benefit of using WRF is that it provides a platform to assess a variety of convection and microphysical schemes.

Three simulations were conducted for the NCEP25 experiment, which were identical except for varying the convective parameterization scheme as follows: Kain-Fritcsh (K-F), Betts-Miller-Janjic (BMJ), and Grell. For NCEP25 and NCEP10 simulations, the initial and boundary conditions were from the National Centers for Environmental Prediction-Final Analysis (NCEP-FNL) (available online at http:// www.rda.ucar.edu) and for NorESM-WRF simulation, the boundary condition was from the Norwegian Earth System Model (NorESM) (Bentsen et al. 2013).
In these simulations, the Unified Noah land-surface and Mellor-Yamada-Janjic Turbulent Kinetic Energy (TKE) boundary layer schemes were employed. The cloud microphysics and radiation schemes used were the WRF single-moment scheme 3 (WSM3) and cam scheme, respectively. Sea surface temperatures (SSTs) in the NorESM and NCEP-FNL were daily and 6-hourly, respectively. The WRF model was run at 30 vertical levels with the model top at $50 \mathrm{hPa}$. Eight outermost rows of the grid points from the lateral boundary are nudged to the forcing dataset in order to preserve the large-scale circulation.

Figure 1 shows the model domains for all the simulations. For NCEP25, a large domain encompassing the wider MC was chosen. For NorESM-WRF and NCEP10, the domain was selected to encompass the areas around Sumatra, Borneo, and the South China Sea (SCS). Both domains were also selected so that the intersection of mountainous terrain and the lateral boundaries of the model domain were minimized as this can introduce spurious wave activities (Zangl 2012).

Two observational datasets were selected to evaluate the modeled precipitation. 1) As a primary dataset: the Tropical Rainfall Measuring Mission (TRMM) 3B42 version 7 precipitation data (Huffman et al. 2007) and 2) as a secondary dataset: the GSMap_MVK+ version 484 precipitation product. More information about the GSMap_MVK+ precipitation product can be found at http://sharaku.eorc. jaxa.jp/GSMapP/index.htm. This product is a microwave radiometer-geostationary infrared combined algorithm and is made by temporal interpolation of 


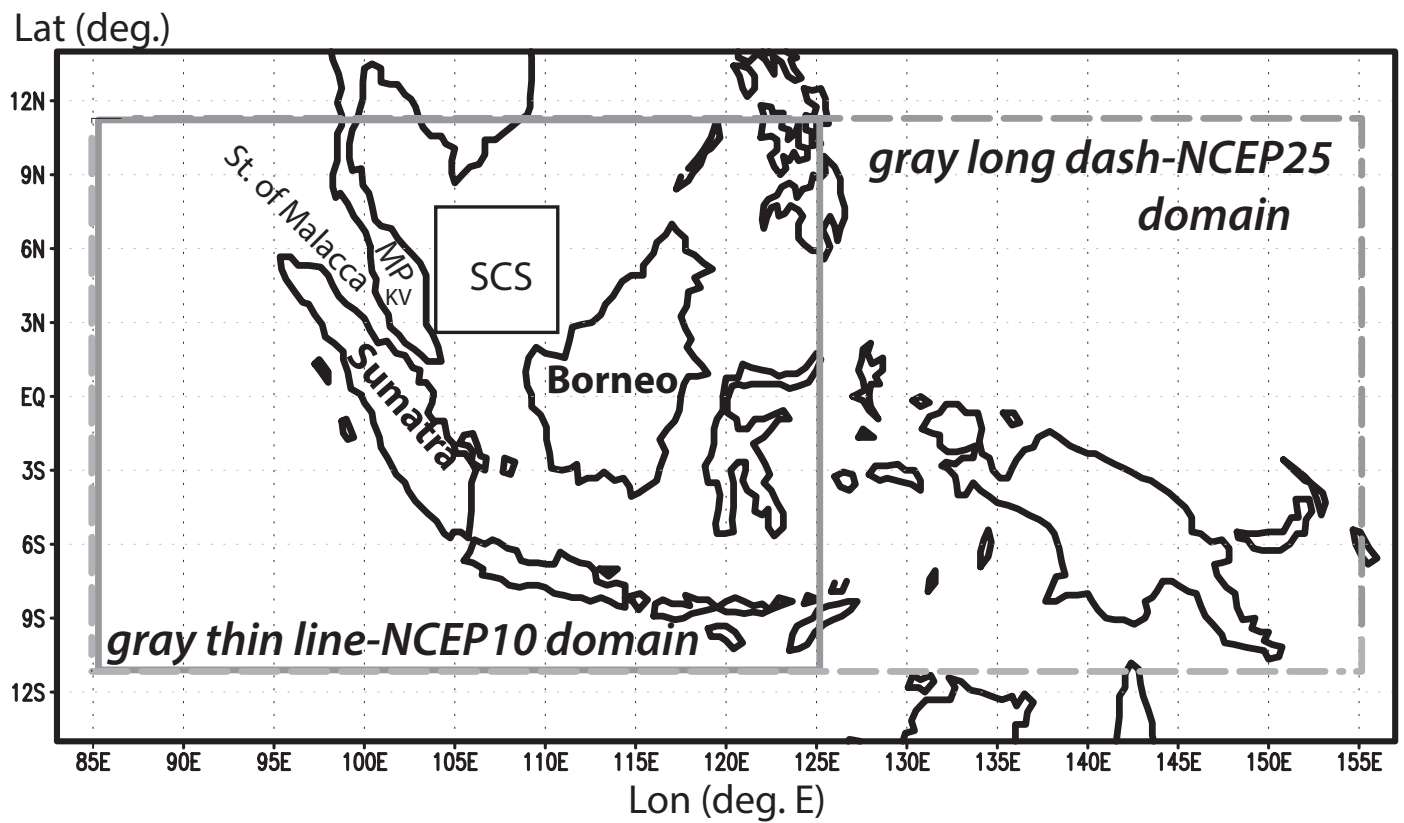

Fig. 1. The panel shows the WRF NCEP25 (long dash line) and NCEP10 (thin line) model domains over the maritime continent. The 3 analysis regions are labelled as Sumatra, Borneo and South China Sea (SCS). The MP is for Malay Peninsula and KV is for Kelang Valley.

the GSMap MVK+ using a morphed technique and a Kalman filter from IR information. Refer to Seto et al. (2009) and Dinku et al. (2010) for further reading.

Two methods were used to analyze and compare the diurnal cycle from modeled and observed precipitation data: discrete Fourier transform (DFT) and empirical orthogonal function (EOF) analysis. The DFT is an elementary spectral method used to transform a time series into a superposition of sinusoidal variations of discrete frequencies, with information on the variance and phase at each frequency. Its implementation in this work follows that of Torrence and Compo (1998). The advantage of DFT is that it is relatively simple to interpret and can be implemented efficiently using the fast Fourier transform algorithm (Press et al. 1992). DFT was applied to the precipitation time series at each grid box, and grid boxes were aggregated to calculate the average over Sumatra, Borneo, and the SCS regions (Fig. 1). These regions are discussed briefly in the next section. The EOF analysis was performed to extract the dominant modes of variability and quantify the spatial and temporal patterns of the diurnal precipitation cycle. Previously, the EOF method was successfully used to explain the principal features of the diurnal cycle of rainfall over global tropics (Kikuchi and Wang 2008).

\section{Results}

\subsection{Mean precipitation}

To begin, we briefly compare mean precipitation climatology between the NCEP25 simulation and the TRMM 3B42 precipitation for the 2000-2005 period. TRMM 3B42 exhibits precipitation maxima over the major islands of the MC such as Sumatra, Borneo, and New Guinea (Fig. 2a). These are reproduced in the NCEP25 simulation (Fig. 2b). But precipitation is overestimated both over land and ocean. The precipitation maxima are collocated with the topography over these three Islands. This clear orographic influence has been previously reported over Sumatra (Mori et al. 2004) and Borneo (Houze et al. 1981). To investigate different timescales of precipitation variability over local land regions, we selected Sumatra and Borneo. In addition to these land regions, we selected a region over the SCS. The complex relationships among circulation features and the MC topography over the SCS contribute to the variability in convection patterns over a variety of space and timescales (Chang et al. 2005). These two major Islands and the SCS are thus ideal choices for studying precipitation variability over the region (Aldrian et al. 2005). 

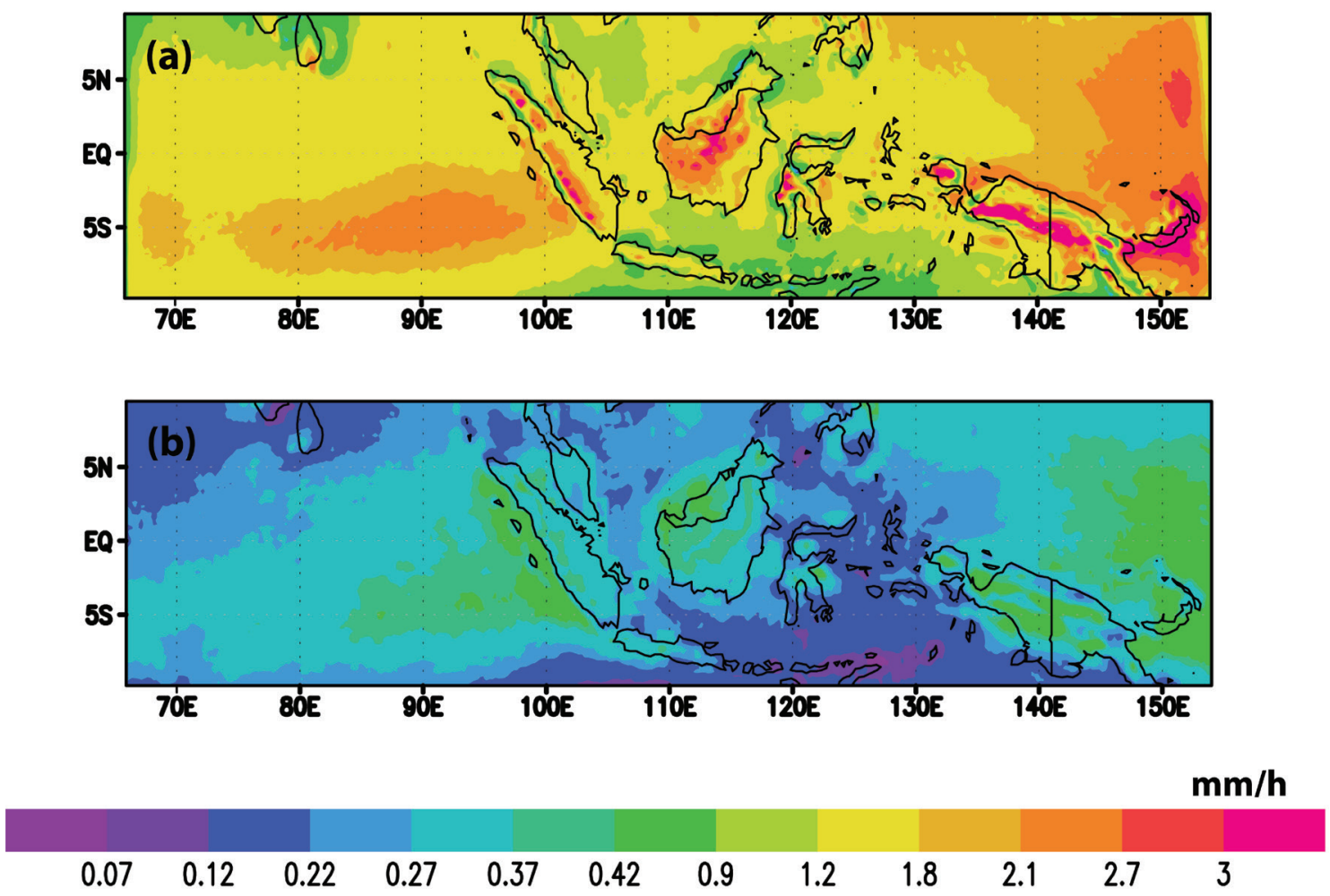

Fig. 2. Comparison between the horizontal distributions of the mean precipitation climatology from (a) the NCEP25 simulation and (b) TRMM 3B42. Refer to the text for discussion.

\subsection{Fourier analyses}

We now turn to the analysis of precipitation over Sumatra, Borneo, and the SCS utilizing the DFT. WRF's ability to simulate temporal modes of diurnal precipitation was evaluated by comparing the precipitation from the three NCEP25 simulations (each employing a different convective scheme, see Section 2) with satellite observed precipitation. This methodology is similar to that used by Knieval et al. 2004, which suggested that examining temporal modes emphasizes some of the most consistent properties of the model's quantitative precipitation predictions. The spectra from WRF and the observations were compared over Sumatra, Borneo, and the SCS (Fig. $3)$. It is apparent intraseasonal and diurnal temporal modes are captured in NCEP25 simulations. The spectral power is stronger in the model than the observations at diurnal timescales and over the inland regions. But at synoptic timescales (i.e., less than 7 days), spectral power is generally too weak from the model. The power of the diurnal mode is the strongest of any time period over all regions. These results emphasize the critical importance of the diurnal cycle for precipitation over the MC. Over the ocean (such as the SCS), performance of $\mathrm{K}-\mathrm{F}$ is relatively better than those of BMJ and Grell. BMJ and Grell both exhibit a fall-off in spectral power relative to observations at about 4 days, whereas $\mathrm{K}-\mathrm{F}$ matches the observed spectral power up to about $6 \mathrm{~h}$. This fall-off in spectral power is also exhibited over land by the BMJ scheme. Over land regions, results from $\mathrm{K}-\mathrm{F}$ and Grell are comparable.

Figure 4 compares the amplitude of the diurnal precipitation cycle (24-h harmonic) between NCEP25 simulations (with different convective schemes) and TRMM 3B42. In TRMM 3B42, relatively larger amplitudes are exhibited over the major islands of the MC than over the open ocean. This is similar to the results from a harmonic analysis of 6 years of observed TRMM data shown in Bowman et al. (2005). All three NCEP25 simulations exhibit too large amplitudes over all regions except the open ocean. The largest amplitude discrepancies appear over the major islands and are generated by the BMJ scheme with only modest improvements under the Grell and $\mathrm{K}-\mathrm{F}$ schemes. Both Grell and $\mathrm{K}-\mathrm{F}$ show a 

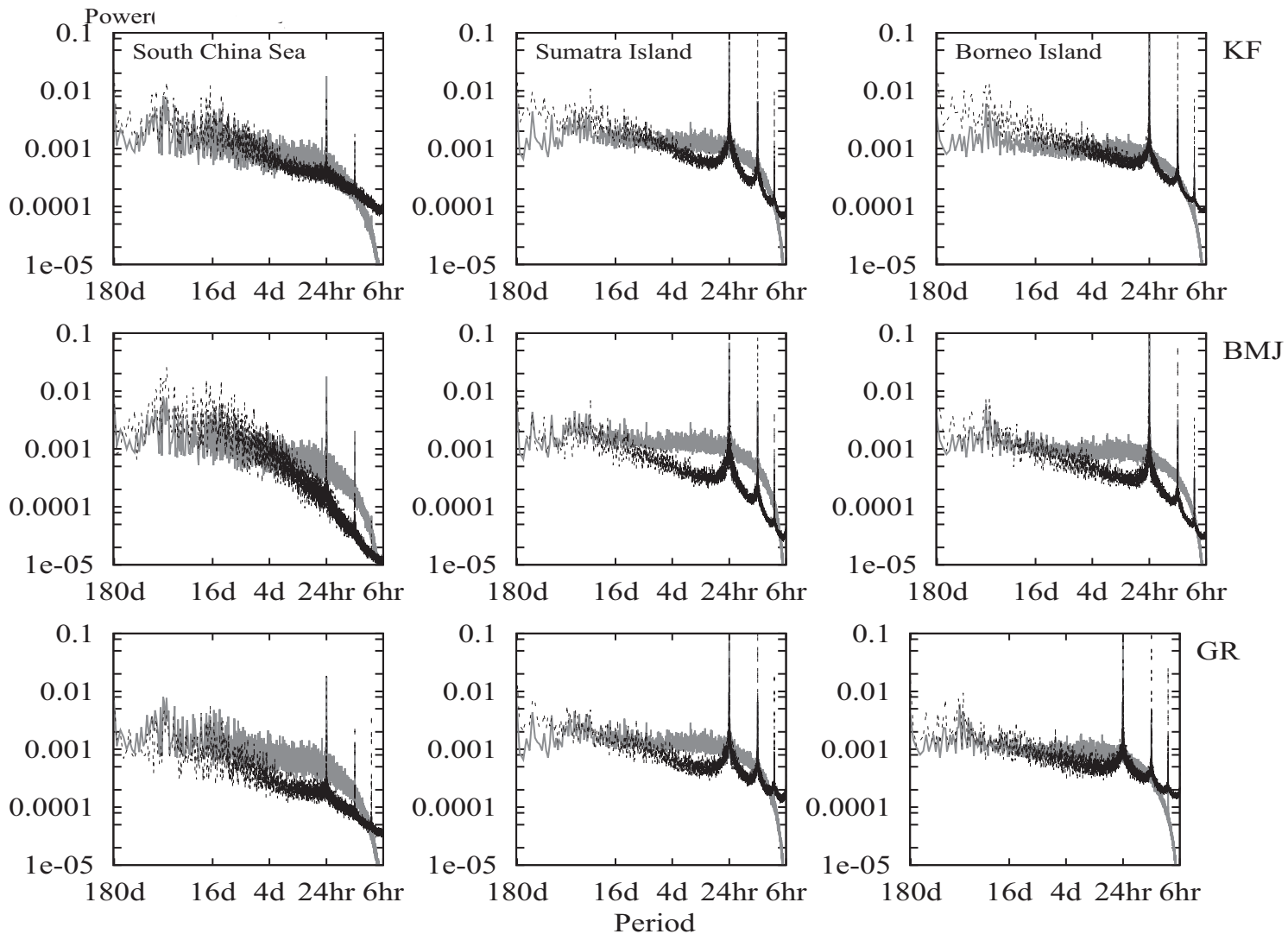

Fig. 3. Fourier power spectra from 3-hourly precipitation time series from TRMM observations (gray) and NCEP25 (black) in log scale. The first, second and third columns show spectra for SCS, Sumatra and Borneo, respectively. The first, second and third rows show spectra from the NCEP25 simulations for the K-F, BMJ and Grell convective schemes, respectively.

clearer separation between coastal and near-coastal precipitation than $\mathrm{BMJ}$, which is closer to the patterns seen in TRMM 3B42. Grell and K-F also capture the precipitation patterns over the mountainous areas of northern Borneo, whereas BMJ largely misses these orographically enhanced peaks. Note that despite capturing the patterns of precipitation, Grell and K-F show substantial biases in amplitude that are equivalent to those seen in BMJ. Despite the amplitude discrepancy, other aspects of the $\mathrm{K}-\mathrm{F}$ simulations performed relatively better (Fig. 3) and are consistent with previous research; therefore, it was chosen as the convective scheme for the high-resolution $(10 \mathrm{~km}$, NCEP10) simulations.

\subsection{Impact of the lateral boundary}

Besides the convective scheme, model performance is sensitive to the choice of the lateral boundary conditions. Here, we compare simulations for the year
2004 to test the model's sensitivity to lateral boundary conditions using two boundary forcings: NCEP10 simulations forced by NCEP-FNL; NorESM-WRF simulation forced by NorESM. Figure 5 shows the average diurnal precipitation cycle for NorESM-WRF (a, b), NCEP10 (c,d) and from observed GSMap data $(e, f)$. Some features are evident in the observed GSMap data such as early morning propagating precipitation over the northwest coast of Borneo and early morning precipitation over the Strait of Malacca and west of Sumatra. In comparison, the early morning propagating precipitation is missing over the northwest coast of Borneo in NorESM-WRF. Also barely visible is the early morning precipitation over the Strait of Malacca and west of Sumatra. Conversely, these features are readily seen in the NCEP10 simulation. Increased precipitation amount is noted from the NorESM-WRF over southwest of Sumatra over the Indian Ocean relative to the 


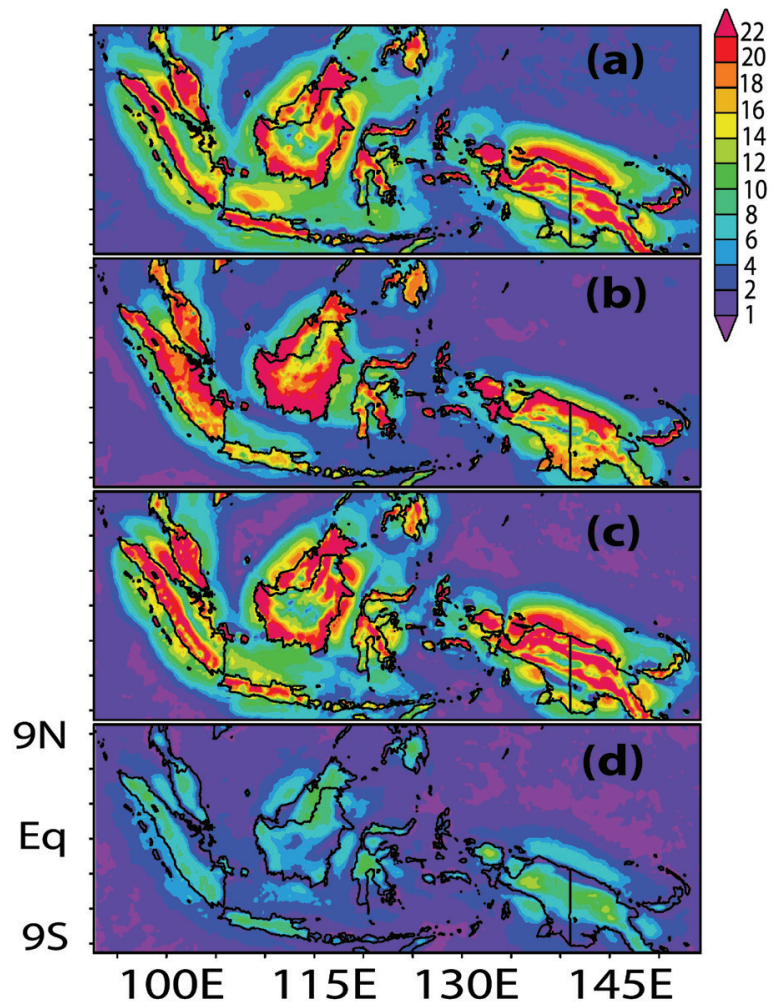

Fig. 4. Amplitude of the 1st harmonic of precipitation from the NCEP25 simulations over the wider maritime continent for 2000-2005 period for the (a) K-F, (b) BMJ, (c) Grell convective schemes, and (d) observed TRMM 3B42. Precipitation units are $\mathrm{mm}$ day ${ }^{-1}$.

NCEP10 simulation. Precipitation amount is small in the observed GSMap data over this sub-region. Over land NorESM-WRF, NCEP10 and the observed GSMap exhibit similar patterns. The higher resolution simulation results in generally more accurate representation of the diurnal precipitation cycle.

As mentioned earlier, the SST treatment in NorESM might have contributed to the misrepresentation of the early morning precipitation patterns. In-depth examination into boundary conditions obtained from the NCEP-FNL and NorESM is beyond the scope of this paper. However, the results suggest that the higher spatial resolution $(1 \mathrm{deg} \times 1 \mathrm{deg})$ of the NCEP-FNL likely better represents the regional dynamics over the tropics than the coarser resolution NorESM ( $2 \mathrm{deg} \times 2 \mathrm{deg}$ ). Furthermore, previous studies (Bentsen et al. 2013) have identified deficiencies such as a double intertropical convergence zone over the tropics and overestimation of tropical precip- itation in NorESM.

\subsection{EOF analysis}

To objectively quantify diurnal precipitation variability over the $\mathrm{MC}$, an EOF analysis was applied to the NCEP10 precipitation output and the TRMM 3B42 observations. As a first step, the averaged 3-hourly diurnal cycle for the year 2004 was computed. In the next step, the EOF analysis was applied. A guide to the EOF method can be found in Jackson (1991). The first two EOFs from NCEP10 are shown in Figs. 6a and 6b. The diurnal precipitation features in TRMM 3B42 observations (Figs. 6c and $6 \mathrm{~d}$ ) are captured within the first two EOFs. The two observed (modeled) EOFs explain 51.0 \% (71.8 $\%)$ and $28.5 \%(21.0 \%)$ of the total diurnal variance. There are differences between modeled and observed variance explained for EOF1; however, EOF2 variances are closer. In the case of model data, the ratio of EOF1 to EOF2 is 3.4; this ratio is higher than that in the observations, implying that the dominant diurnal mode is overly strong in the model.

Figure 7a shows that EOF1 can be expressed by the diurnal difference between afternoon (Hour 16) and morning (Hour 7) from TRMM 3B42. Similarly, EOF2 can be represented by the diurnal difference between late evening (Hour 22) and about noon (Hour 13) (Fig. 7b). The diurnal difference for the NCEP10 data is also shown (Figs. 7c, d). Note that the nocturnal precipitation features, which appear in the observations, are only weakly reproduced in NCEP10 (Fig. 7d). The reason for this discrepancy is not known but may be due to too weak convergence over inland areas in NCEP10. The positive loading on EOF1 from TRMM 3B42 appears inland and indicates afternoon precipitation as principal component 1 (PC1) has a maximum in the afternoon (Fig. 8). The positive spatial loading of EOF2 in TRMM 3B42 appears mostly over the coasts and indicates nighttime precipitation features as principal component 2 (PC2) has its maximum around midnight (Fig. 8). The NCEP10 PC1 and PC2 both lead the observed PC time series by about $3 \mathrm{~h}$. A similar finding has been reported in other regional modeling studies (e.g., Koo and Hong 2010; Teo et al. 2011) and these previous studies attributed this to the inadequate representation of the transition from shallow to deep convection by the convective parameterization within the WRF model.

EOF1 represents a typical tropical diurnal precipitation signal characterized by contrasting land-sea regime that features an afternoon peak over land and an early morning peak over the ocean. This may be 

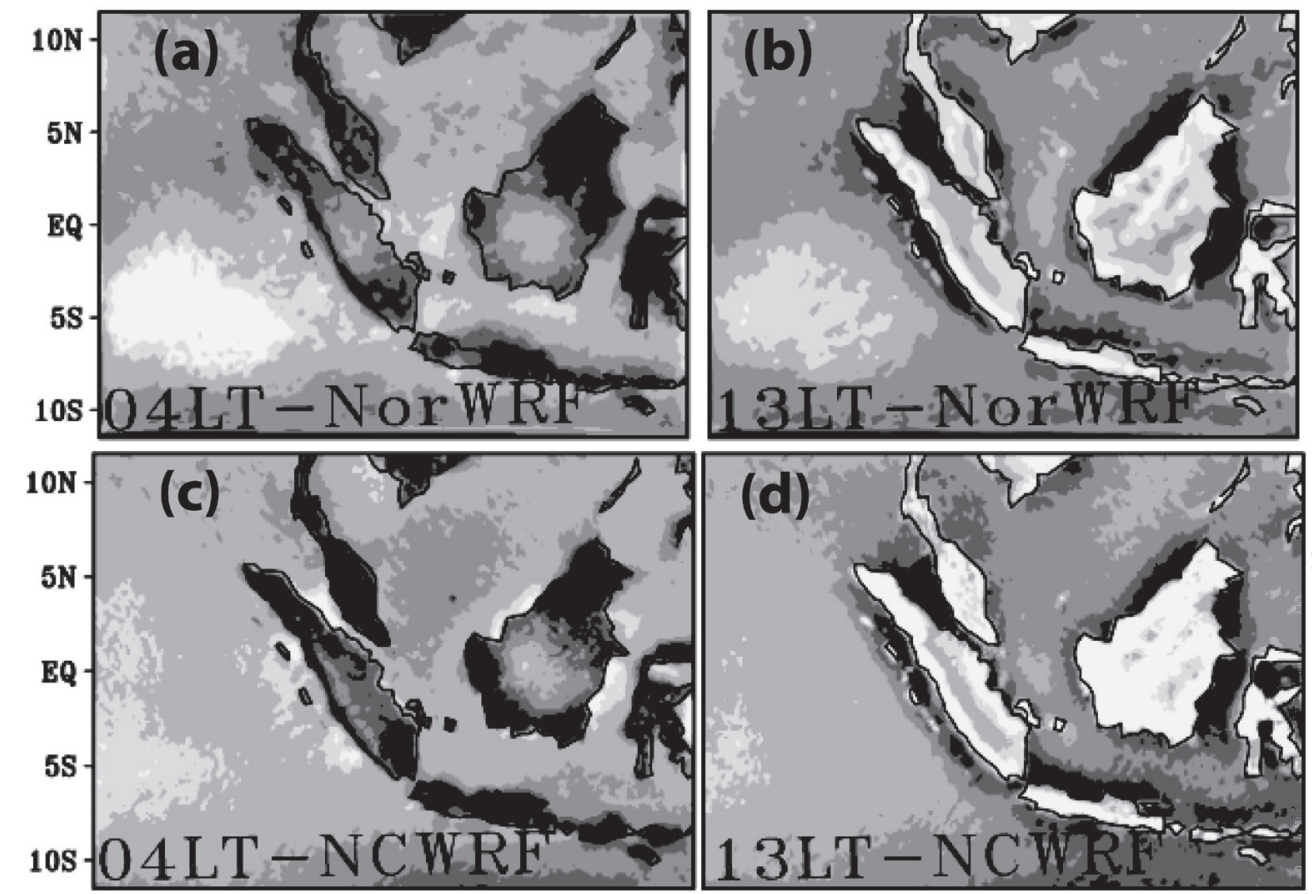

$\mathrm{mm} / \mathrm{h}$
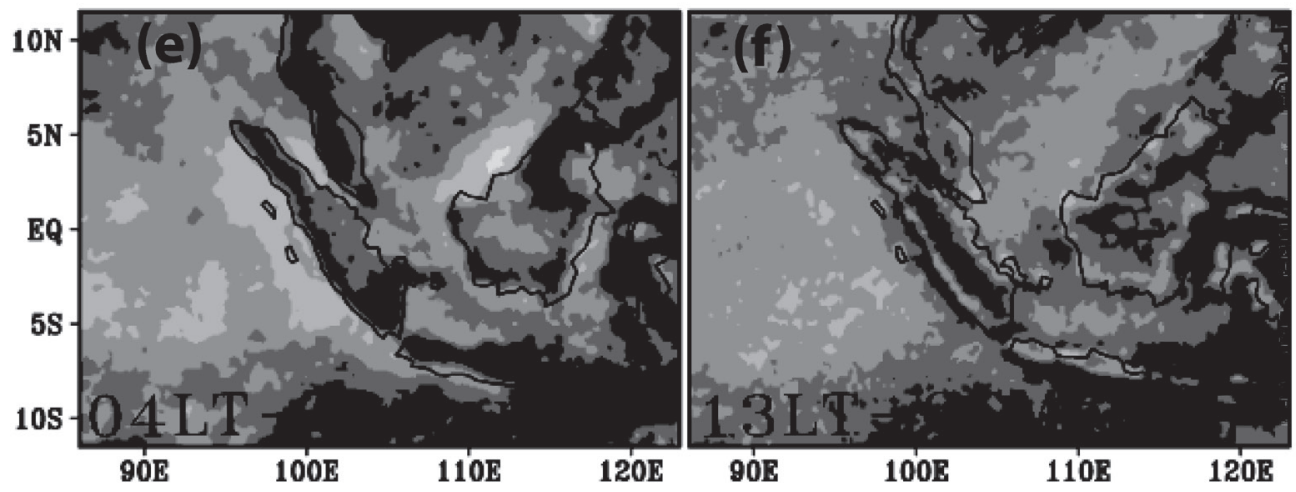

Fig. 5. The spatial pattern of the diurnal cycle of precipitation for the year 2004 for a range of boundary conditions: (a) and (b) (04 and 13LT) WRF simulations using NorESM; (c) and (d) (04 and 13LT) WRF simulations using NCEP-FNL boundary conditions; (e) and (f) (04 and 13 LT) observed GSMap data. Panels show the diurnal cycle with early morning maxima over the ocean/near shore waters (a), (c), (e) and afternoon maxima over land (b), (d), (f).

described as a land-sea contrast mode. The afternoon peak over land is due to the solar heating-induced maximum in convective available potential energy, which favors convection (Dai 2001; Kikuchi and Wang 2008). There could be multiple causes behind early morning convection over the ocean, and it can be enhanced by cloud-top cooling relative to nearby clear areas (Gray and Jacobson 1977). EOF2 represents the local nocturnal rain features over inland and coastal land and sea, resulting from local thermally induced circulations or from the interaction between mesoscale convection and gravity waves. Gravity waves due to localized convection over western Sumatra during April-May 2004 have been reported in the analysis of Venkat Ratnam et al. (2006).

\subsection{Local circulation patterns}

Here, we briefly describe the circulation over the $\mathrm{MC}$ in the lower atmosphere and discuss how its 


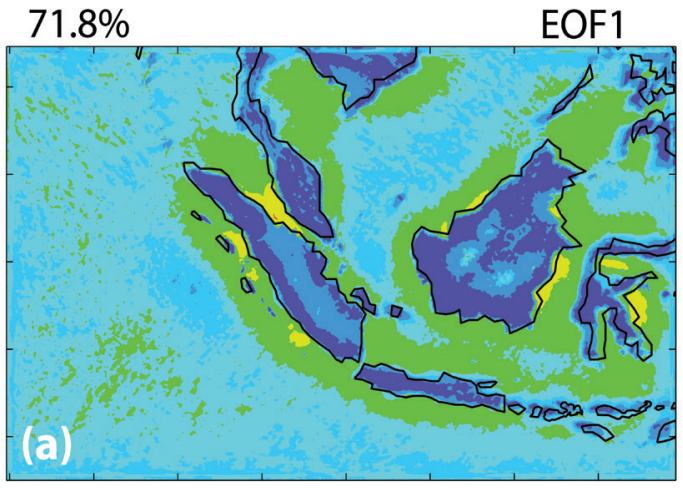

$51.0 \%$

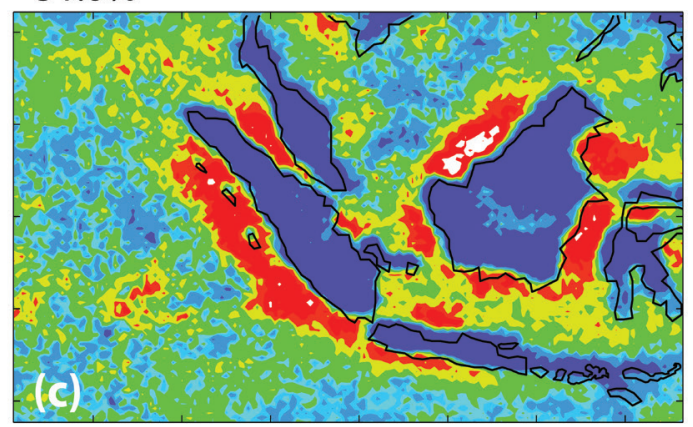

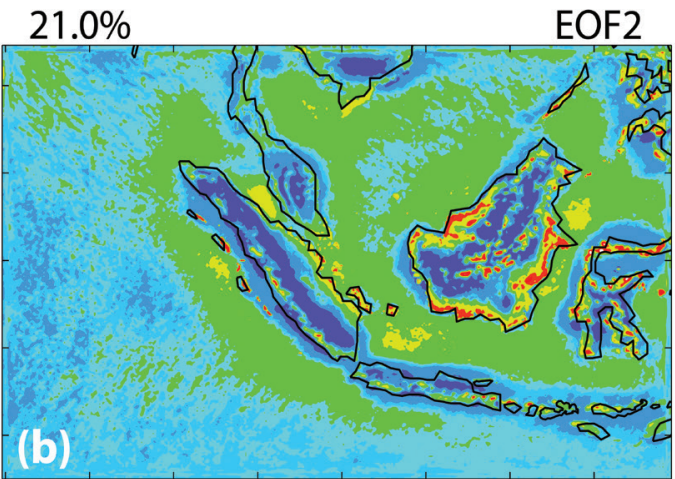

\section{$28.5 \%$}

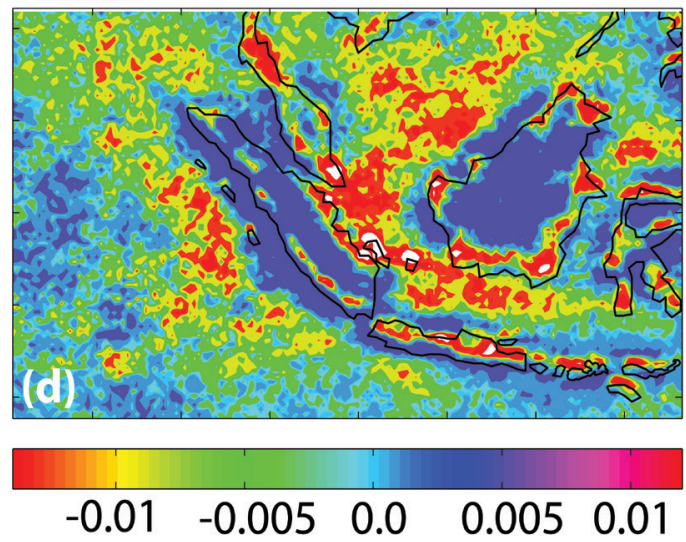

Fig. 6. The spatial patterns of the first two EOF modes (left panels: EOF1 and right panels: EOF2) of the diurnal precipitation from NCEP10 (a), (b) and TRMM 3B42 (c), (d). The variance explained for each EOF is shown in the top.

mechanisms are represented in the WRF simulations and thereby contribute to the simulated diurnal precipitation patterns. The land-sea breeze circulation is a common feature over the MC (Teo et al. 2011; Joseph et al. 2008). Diurnal land-sea temperature variations occur as a result of the low heat capacity of land compared with that of water. When the near-shore water temperature is close to the diurnal mean of the land temperature, the land will tend to be warmer than the water in daytime and cooler during nighttime. This produces a solenoidal circulation between land and water, resulting in a land breeze/sea breeze depending on whether it is night/day (Yang and Smith 2006). Observational studies carried out over specific islands within the MC have described the large influence that local circulations in the form of land-sea breezes may have on precipitation. Ichikawa and Yasunari (2006) described the diurnal precipitation cycle over Borneo using TRMM data and showed that precipitation begins along the coast and moves toward the central mountains and is strengthened in the afternoon due to confluence of the onshore and upslope winds. Wu et al. (2009) showed that upslope winds driven by diurnal heating at the surface of the mountains reinforces the daytime sea breeze over the western coast of Sumatra.

To evaluate the ability of the NCEP10 simulation to reproduce these local circulations, the diurnal variations in the near-surface wind fields and temperature are shown in Fig. 9. The simulated near-surface winds and temperatures clearly show a diurnal cycle. Sea-breeze fronts converge over inland Borneo in the late afternoon. Likewise, strengthening of the winds can be seen along the west coast of Sumatra from early afternoon to late afternoon. After midnight, especially between 1 and 2 LT, winds converge over the Straits of Malacca (Fig. 10 and c.f. Fig. 1). Hara et al. (2009) also noted a clear diurnal cycle in surface 

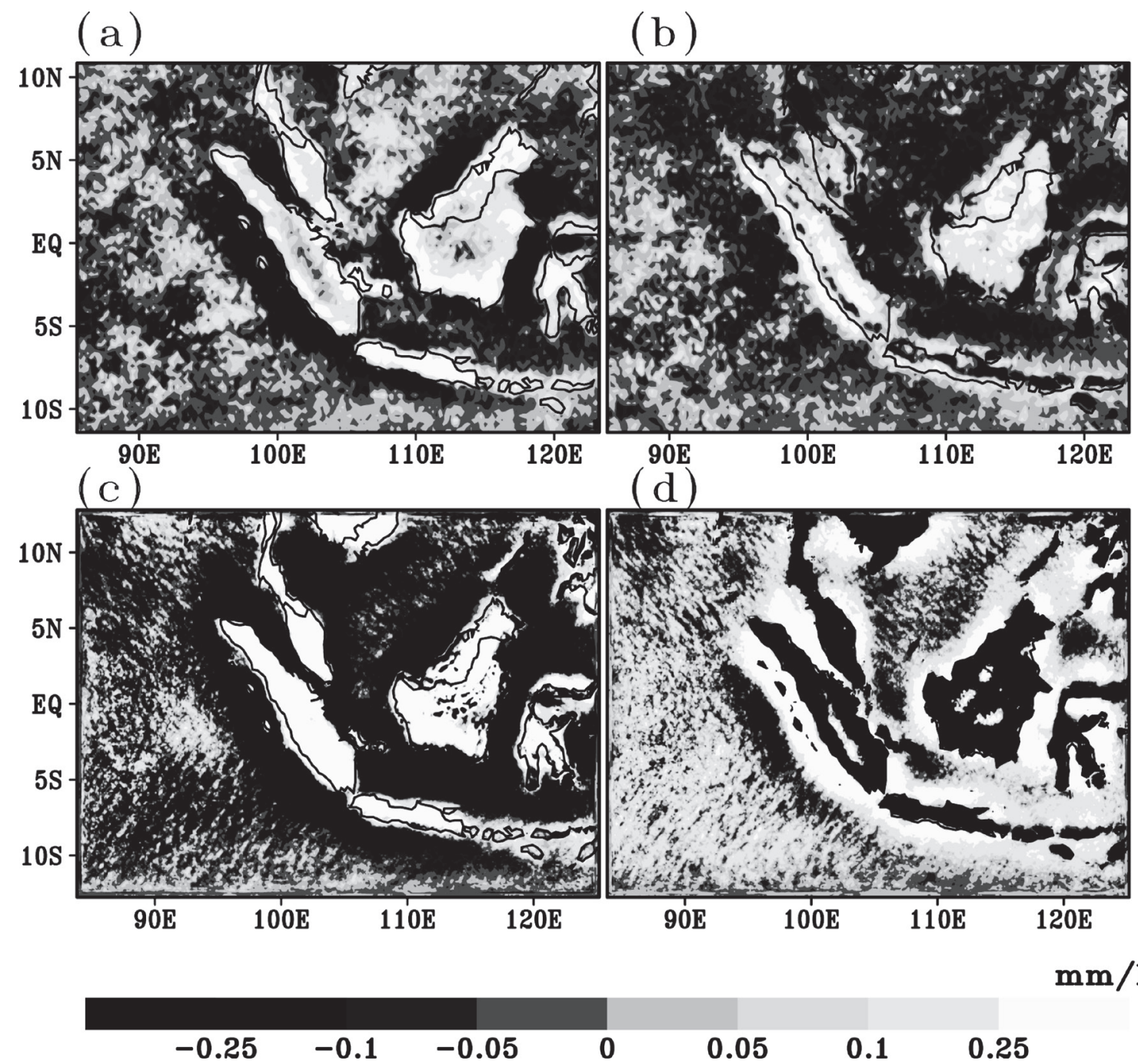

$\mathrm{mm} / \mathbf{h}$

Fig. 7. The diurnal precipitation variability: (a) afternoon (16LT) minus morning (07LT) precipitation rate in TRMM 3B42; (b) late evening (22LT) minus midday (13LT) precipitation rate in TRMM 3B42; (c) afternoon (16LT) minus morning (07LT) precipitation rate in NCEP10; (d) late evening (22LT) minus midday (13LT) precipitation rate in NCEP10. The land-sea contrast mode (EOF1) and transition mode (EOF2) can be represented by the diurnal differences shown here. Refer to text for more detailed discussion.

winds over the inland Borneo, coastal Sumatra, and Straits of Malacca.

The expected daytime heating and nighttime cooling is also appropriately simulated. At 14 LT, there is high temperature over the inland Borneo, Sumatra, and Malay Peninsula. Over central Borneo and the western coast of Sumatra, temperatures begin to drop in the evening and reach a minimum between 3 and 4 LT (Fig. 10). Results from NCEP10 demonstrate that the WRF can reasonably reproduce the diurnal radiatively induced land-sea breeze circula- tion over the $\mathrm{MC}$, which is crucial for the representation of the diurnal precipitation patterns described previously. However, local circulations such as those described in Joseph et al. (2008), i.e., interactions between sea breeze and gap winds over the Kelang Valley (Fig. 1) in the central Malay Peninsula and interactions between sea breezes and lee waves in the north-western Malay Peninsula, are not resolved. The use of even higher resolution numerical simulations or combined dynamical-statistical techniques will likely be needed to properly capture these types of circula- 


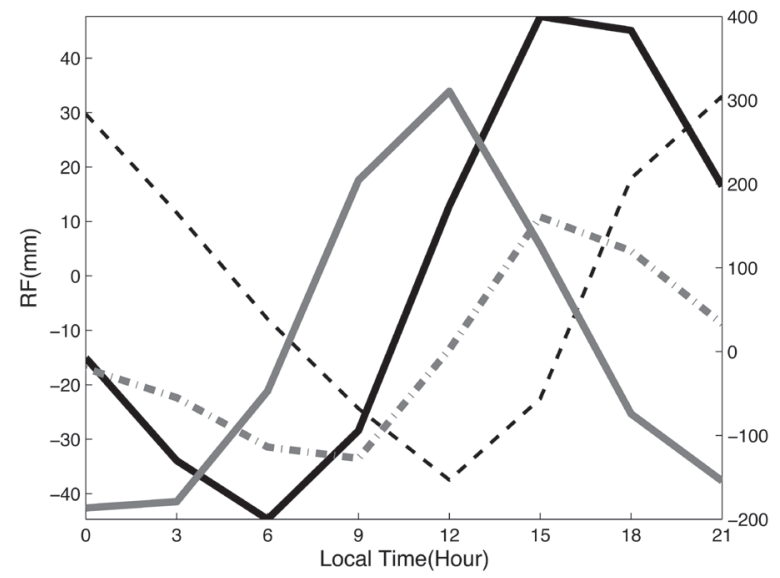

Fig. 8. The principal component scores corresponding to the EOFs in Fig. 6. NCEP10 is plotted in right-axis using gray solid (PC1) and gray dashed (PC2). TRMM3B42 is plotted in left-axis using black solid (PC1) and black dashed (PC2).

tions.

\section{Discussion and conclusions}

A realistic depiction of the diurnal cycle of precipitation is likely fundamental for skillful numerical modeling of the atmosphere and the reliable representation of any future changes in precipitation over the tropics in general and the MC in particular. We have focused our study on the diurnal cycle of precipitation in the belief that investigations of high-resolution simulations of the diurnal cycle may have a positive impact on understanding of climate variability under both present and projected future conditions.

This work contributes to our understanding of the limitations of the WRF with respect to simulations of tropical precipitation, at least for the period of analysis. Some cumulus parameterizations are found relatively less appropriate for tropical applications than others. For example, we noted, from spectral analysis, that $\mathrm{K}-\mathrm{F}$ relatively performs better than BMJ and Grell over the MC. This better performance by $\mathrm{K}-\mathrm{F}$ has also been reported in earlier precipitation modeling studies over the MC (Joseph et al. 2008; Teo et al. 2011; Koseki et al. 2012). The shortcomings of the WRF simulations suggest that other aspects of the parameterizations are inadequate, and it is possible that there are compensating errors and/or error dependencies, which will require more detailed investigation.
The WRF model simulation captures the precipitation diurnal cycle well compared with TRMM 3B42 although the model overestimates the amplitude. The exaggerated precipitation amplitude over land by all the WRF simulation indicates that mechanisms related to boundary layer transfer and convective lifting-condensation-precipitation are likely not well reproduced by the respective parameterization schemes. Convection permitting scales $(<4 \mathrm{~km})$ may be necessary in order to better diagnose and address these issues.

Some mesoscale processes that contribute to diurnal convection are not represented by WRF. Lack of representation of these processes contributes to errors in the simulation of the diurnal cycle. For example, WRF has reasonably reproduced the land-sea breeze over MC (Figs. 9, 10) and thus to first order reproduces the driving mechanisms for the diurnal precipitation, namely differential land-ocean heating. However, it is not known to whether or not the reproduced sea breezes are of the proper strength. Also, local circulations such as those described in Joseph et al. (2008), i.e. interaction between sea breeze and gap winds over the Kelang Valley in the central Malay Peninsula; interaction between sea breeze and lee waves in the north-western Malay Peninsula; collision between two sea breezes over the southern Malay Peninsula, are not resolved. These aspects of sea breeze related circulation often regulate intense thunderstorm development and contribute to diurnal precipitation over Malay Peninsula (Joseph et al. 2008; Sow et al. 2011).

The two leading EOF's can explain most of the variation of diurnal precipitation. The first EOF is strongest and represents the fundamental atmospheric response to potential instability forced by radiation and surface heat flux over land (sea) during day (night). The second EOF shows that WRF is able to reproduce some of the local nocturnal precipitation features like those of inland Borneo. However, the precipitation features across the coastal boundaries are not well reproduced. These shortcomings are likely due to deficiencies within the convective parameterization (interacting with boundary layer and land surface schemes). Furthermore, the NCEP10 PC1 and PC2 both lead TRMM 3B42 by about $3 \mathrm{~h}$ over the MC. The exact cause for this mismatch in timing is not known but commonly described shortcomings that could contribute are under representation of cloud development (Guichard et al. 2004) and lateral entrainment-detrainment rates in deep and shallow convection (Wang et al. 2007). The other contribution could be from the strong relationship between model 

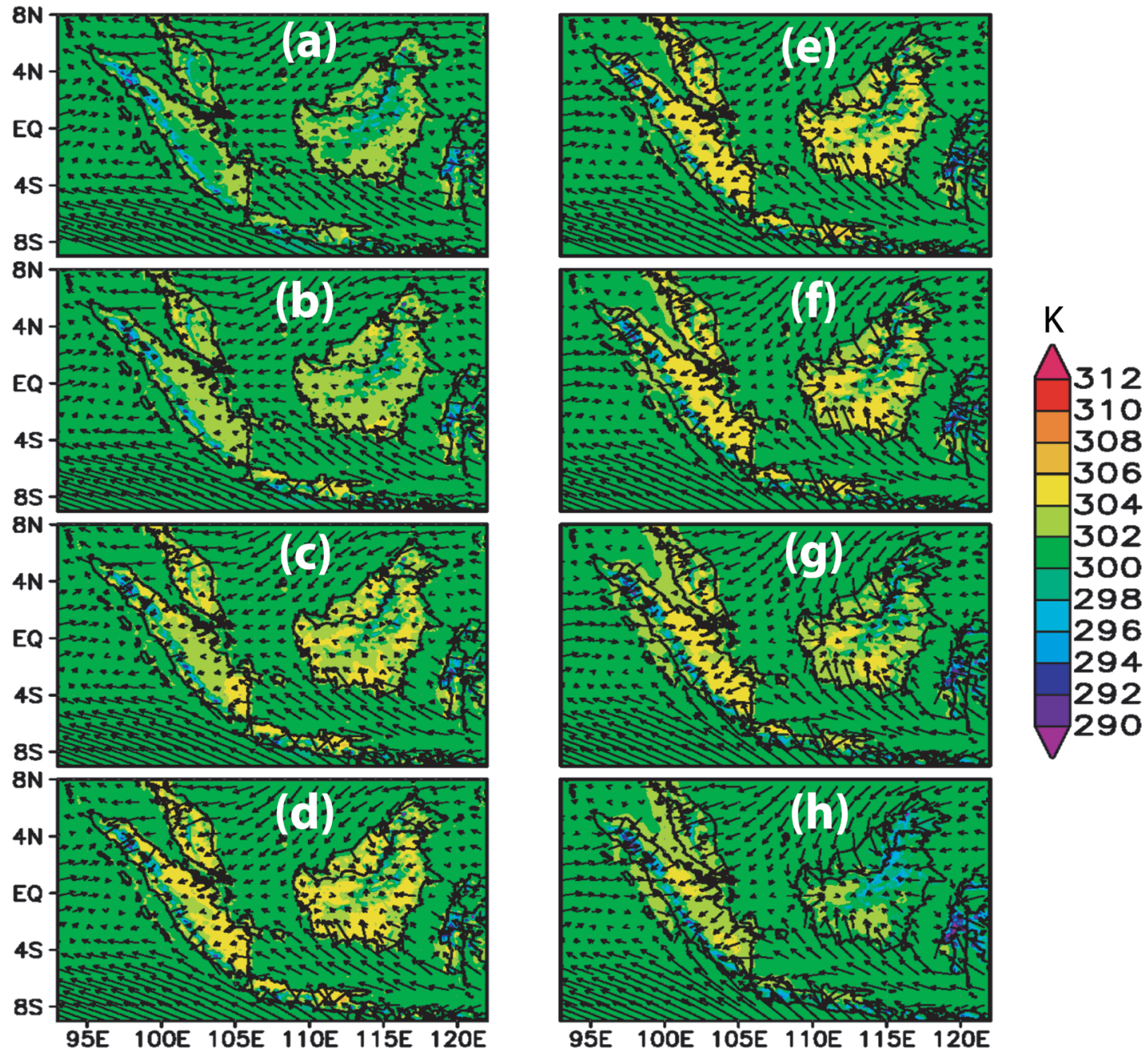

$2.5 \mathrm{~m} / \mathrm{s}$

Fig. 9. Diurnal cycle for different local times for the year 2004 from NCEP10: (a) 11LT, (b) 12LT, (c) 13 LT, (d) $14 \mathrm{LT}$, (e) $15 \mathrm{LT}$, (f ) $16 \mathrm{LT}$, (g) $17 \mathrm{LT}$, and (h) $18 \mathrm{LT}$. The near surface temperature and 10m wind are shown by shades and vectors (black arrows).

convection and convective available potential energy (Lee et al. 2007a). These shortcomings indicate gaps in our understanding that need to be filled in order to improve the representation of the diurnal precipitation cycle.

The NCEP-FNL is from the Global Data Assimilation System, and the higher spatial resolution of the NCEP-FNL data or the SST treatment in the NCEP-FNL might have contributed to the better simulation of the diurnal cycle in NCEP10 than NorESMWRF, at least for the period of analysis. This study supports previous work, which concludes that the NCEP lateral boundary conditions lead to reasonable simulation of the diurnal cycle over the MC. For example, Qian (2008) shows that RegCM3-BATS1e, driven by the NCEP reanalysis lateral boundary conditions, simulates the diurnal precipitation cycle over the island of Java well. There is a need, however, to further test the impact of different boundary conditions, domain sizes, and resolution jumps on the simulation of the diurnal cycle of precipitation.

Finally, it should be noted that while we believe 

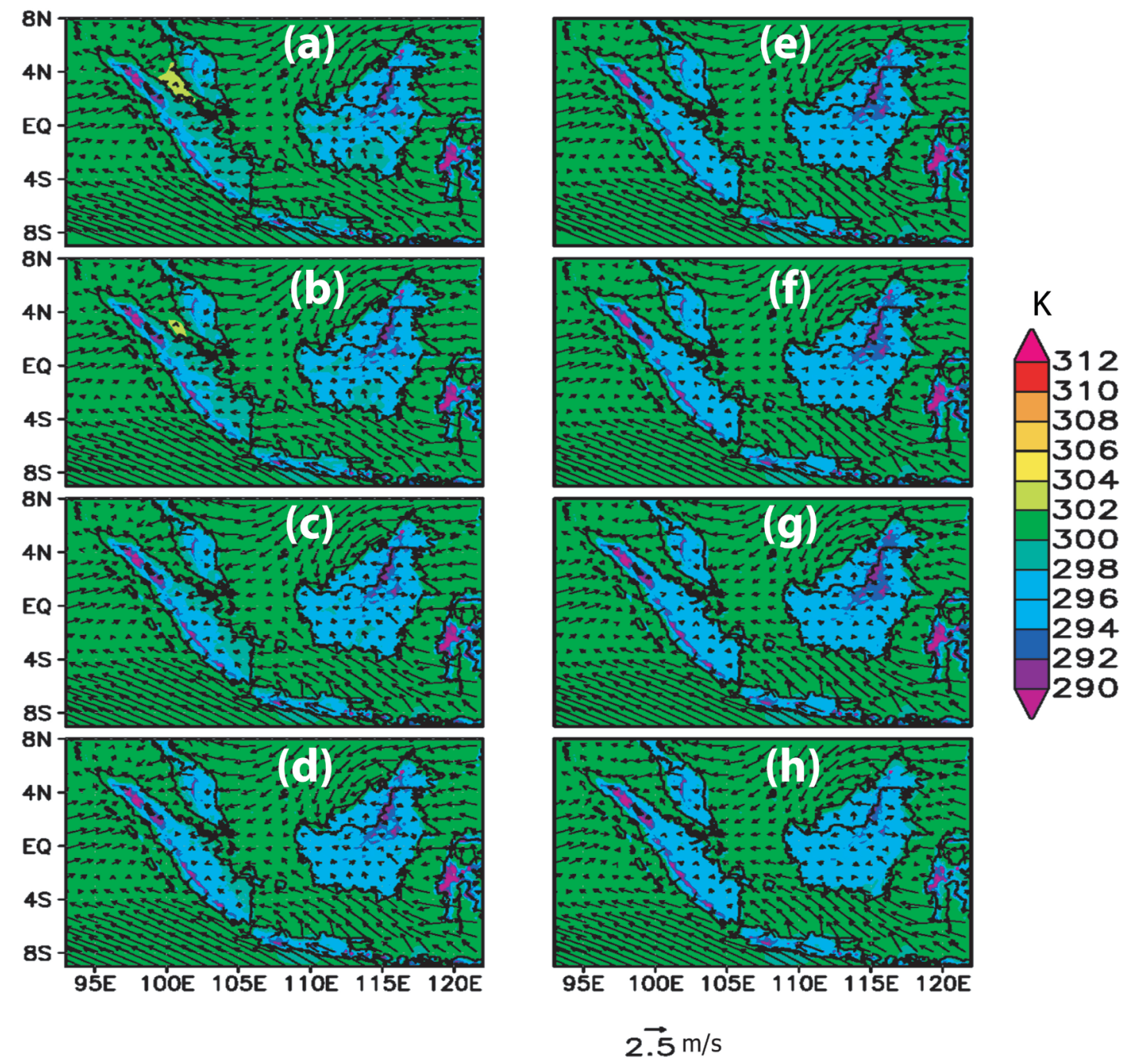

Fig. 10. Same as Fig. 9 but for: (a) 00LT, (b) 01LT, (c) 02 LT, (d) 03 LT, (e) 04 LT, (f) 05 LT, (g) 06 LT, and (h) 07 LT.

the 1-year period is long enough to resolve the salient features of the diurnal precipitation cycle, this period is not long enough to compute robust climate statistics or evaluate interannual variability. Thus, there is a need for longer experiments that can creatively balance the added value that increase in resolution brings with the additional computational cost of running many simulations in order to improve statistical robustness.

\section{Acknowledgments}

The authors are thankful to the reviewers for their valuable comments. We thank Teo Chee Kiat for valuable discussion in the paper. Some of the WRF simu- lations were performed in part by using the computing facility at the Uni Research Climate.

\section{References}

Aldrian, E., D. Sein, D. Jacob, L. D. Gates, and R. Podzun, 2005: Modelling Indonesian rainfall with a coupled regional model. Climate Dyn., 25, 1-17.

Bentsen, M., I. Bethke, J. B. Debernard, T. Iversen, A. Krikevag, O. Seland, H. Drange, C. Roelandt, I. A. Seierstad, C. Hoose, and J. E. Kristjansson, 2013: The Norwegion Earth System Model, NorESM1-M-Part 1: Description and basic evaluation of the physical climate. Geosci. Model Dev., 6, 687-720.

Bowman, K. P., J. C. Collier, G. R. North, Q. Wu, E. 
Ha, and J. Hardin, 2005: Diurnal cycle of tropical precipitation in Tropical Rainfall Measuring Mission (TRMM) satellite and ocean buoy rain gauge data. J. Geophys. Res, 110, D21104, doi:10.1029/2005JD005763.

Chang, C.-P., Z. Wang, J. MacBride, and C.-H. Li, 2005: Annual cycle of Southeast Asia-Maritime Continent rainfall and asymmetric monsoon transition. $J$. Climate, 18, 287-301.

Dai, A., 2001: Global precipitation and thunderstorm frequencies. Part II: Diurnal variations. J. Climate, 14, 1112-1128.

Dai, A., 2006: Precipitation characteristics in eighteen coupled climate models. J. Climate, 19, 4605-4630.

Dai, A., and K. E. Trenberth, 2004: The diurnal cycle and its depiction in the community climate system model. $J$. Climate, 17, 930-951.

Dinku, T., P. Ceccato, K. Cressman, and S. J. Conner, 2010: Evaluating detection skills of satellite rainfall estimates over desert locust recession regions. J. Appl. Meteor. Climatol., 49, 1322-1332.

Dirmeyer, P. A., B. A. Cash, J. L. Kinter III, T. Jung, L. Marx, M. Satoh, C. Stan, H. Tomita, P. Towers, N. Wedi, D. Achuthavarier, J. M. Adams, E. L. Altshuler, B. Huang, E. K. Jin, and J. Manganello, 2012: Simulating the diurnal cycle of rainfall in global climate models: resolution versus parameterization. Climate Dyn., 39, 399-418.

Gianotti, R. L., D. Zhang, and E. A. Eltahir, 2012: Assessment of the regional climate model version 3 over the maritime continent using different cumulus parameterization and land surface schemes. J. Climate, 25, 638-656.

Gray, W. M., and R. W. Jacobson, Jr., 1977: Diurnal variation of deep cumulus convection. Mon. Wea. Rev., 105, 1171-1188.

Guichard, F., J. C. Petch, J.-L. Redelsperger, P. Bechtold, J.-P. Chaboureau, S. Cheinet, W. Grabowski, H. Grenier, C. G. Jones, M. Kohler, J.-M. Piriou, R. Tailleux, and M. Tomasini, 2004: Modelling the diurnal cycle of deep precipitating convection over land with cloud-resolving models and single-column models. Quart. J. Roy. Meteor. Soc., 130, 3139-3172.

Hara, M., T. Yoshikane, H. G. Takahashi, F. Kimura, A. Noda, and T. Tokioka, 2009: Assessment of the diurnal cycle of precipitation over the Maritime continent simulated by a $20-\mathrm{km}$ mesh GCM using TRMM PR data. J. Meteor. Soc. Japan, 87A, 413-424.

Houze, Jr., R. A., S. G. Geotis, F. D. Marks, Jr., and A. K. West, 1981: Winter monsoon convection in the vicinity of north Borneo. Part I: Structure and time variation of the clouds and precipitation. Mon. Wea. Rev., 109, 1595-1614.

Huffman, G. J., D. T. Bolvin, E. J. Nelkin, D. B. Wolff, R. F. Adler, G. Gu, Y. Hong, K. P. Bowman, and E. F. Stocker, 2007: The TRMM multisatellite precipitation analysis (TMPA): Quasi-global, multiyear, combinedsensor precipitation estimates at fine scales. J. Hydrometeor., 8, 38-55.

Ichikawa, H., and T. Yasunari, 2006: Time-space characteristics of diurnal rainfall over Borneo and surrounding oceans as observed by TRMM-PR. J. Climate, 19, 1238-1260.

Jackson, J. E., 1991: A User 's Guide to Principal Components. John Wiley and Sons, 569 pp.

Joseph, B., B. C. Bhatt, T.-Y. Koh, and S. Chen, 2008: Sea breeze simulation over the Malay Peninsula in an intermonsoon period. J. Geophys. Res., 113, D20122, doi:10.1029/2008JD010319.

Jourdain, N. C., A. S. Gupta, A. S. Taschetto, C. C. Ummenhofer, A. F. Moise, and K. Ashok, 2013: The Indo-Australian monsoon and its relationship to ENSO and IOD in reanalysis data and the CMIP3/ CMIP5 simulations. Climate Dyn., 41, 3073-3102.

Kikuchi, K., and B. Wang, 2008: Diurnal precipitation regimes in the global tropics. J. Climate, 21, 26802696.

Kitoh, A., and O. Arakawa, 2005: Reduction in tropical rainfall diurnal variation by global warming simulated by a $20-\mathrm{km}$ mesh climate model. Geophys. Res. Lett., 32, L18709, doi:10.1029/2005GL023350.

Knievel, J. C., D. A. Ahijevych, and K. W. Manning, 2004: Using temporal modes of rainfall to evaluate the performance of a numerical weather prediction model. Mon. Wea. Rev., 132, 2995-3009.

Koo, M.-S., and S.-Y. Hong, 2010: Diurnal variations of simulated precipitation over East Asia in two regional climate models. J. Geophys. Res., 115, D05105, doi:10.1029/2009JD012574.

Koseki, S., T.-Y. Koh, and C. K. Teo, 2012: Effects of the cold tongue in the south China sea on the monsoon diurnal cycle and rainfall in maritime continent. Quart. J. Roy. Meteor. Soc., 139, 1566-1582.

Lee, M.-I., S. D. Schubert, M. J. Suarez, I. M. Held, N.-C. Lau, J. J. Ploshay, A. Kumar, H.-K. Kim, and J. K. E. Schemm, 2007a: An analysis of the warm-season diurnal cycle over the continental United States and northern Mexico in general circulation models. $J$. Hydrometeor, 8, 344-366.

Lee, M.-I., S. D. Schubert, M. J. Suarez, I. M. Held, A. Kumar, T. L. Bell, J. K. E. Schemm, N.-C. Lau, J. J. Ploshay, and H.-K. Kim, S.-H. Yoo, 2007b: Sensitivity to horizontal resolution in the AGCM simulations of warm season diurnal cycle of precipitation over the United States and northern Mexico. $J$. Climate, 20, 1862-1881.

Mak, M. K., and J. E. Walsh, 1976: On the relative intensities of sea and land breezes. J. Atmos. Sci., 33, 242-251.

Mori, S., J.-I. Hamada, Y. I. Tauhid, M. D. Yamanaka, N. Okamoto, F. Murata, N. Sakurai, H. Hashiguchi, and T. Sribimawati, 2004: Diurnal land-sea rainfall peak 
migration over Sumatera Island, Indonesian maritime continent, observed by TRMM satellite and intensive rawinsonde soundings. Mon. Wea. Rev., 132, 20212039.

Neale, R., and J. Slingo, 2003: The maritime continent and its role in the global climate: A GCM study. $J$. Climate, 16, 834-848.

Philander, S. G., 2008: Is the Temperature Rising?: The uncertain science of global warming. Princeton University press, $148 \mathrm{pp}$.

Press, W. H., S. A. Teukolsky, W. T. Vetterling, and B. P. Flannery, 1992: Numerical Recipes in C: The Art of Scientific Computing, 2nd edition. Cambridge University Press, 243-262.

Qian, J. H., 2008: Why precipitation is mostly concentrated over islands in the Maritime continent. J. Atmos. Sci., 65, 1428-1441.

Randall, D. A., Harshvardhan, and D. A. Dazlich, 1991: Diurnal variability of hydrologic cycle in a general circulation model. J. Atmos. Sci., 48, 40-62.

Sato, T., H. Miura, M. Satoh, Y. N. Takayabu, and Y. Wang, 2009: Diurnal cycle of precipitation in the tropics simulated in a global cloud-resolving model. $J$. Climate, 22, 4809-4826.

Seto, S., T. Kubota, T. Iguchi, N. Takahashi, and T. Oki, 2009: An evaluation of over-land rain rate estimates by the GSMap and GPROF algorithms: The role of lower-frequency channels. J. Meteor. Soc. Japan, 87A, 183-202.

Skamarock, W. C., J. B. Klemp, J. Dudhia, D. O. Gill, D. M. Barker, M. G. Duda, X.-Y. Huang, W. Wang, and J. G. Powers, 2008: A description of the advanced research WRF version 3. NCAR Tech. Note, NCAR/ TN-475+STR, 113 pp.

Sow, K. S., L. Juneng, F. T. Tangang, A. G. Hussin, and M. Mahmud, 2011: Numerical simulation of a severe later afternoon thunderstorm over Peninsular Malaysia. Atmos. Res., 99, 248-262.

Teo, C.-K., T.-Y. Koh, J. C.-F. Lo, and B. C. Bhatt, 2011: Principal component analysis of observed and modeled diurnal rainfall in the Maritime Continent. $J$. Climate, 24, 4662-4675.

Torrence, C., and G. P. Compo, 1998: A practical guide to wavelet analysis. Bull. Amer. Meteor. Soc., 79, 61-78.

Venkat Ratnam, M., T. Tsuda, Y. Shibagaki, T. Kozu, and S. Mori, 2006: Gravity wave characteristics over the equator observed during the CPEA campaign using simultaneous data from multiple stations. J. Meteor. Soc. Japan, 84A, 239-257.

Wang, Y., L. Zhou, and K. Hamilton, 2007: Effect of convective entrainment/detrainment on the simulation of the tropical precipitation diurnal cycle. Mon. Wea. Rev., 135, 567-585.

Wu, P., M. Hara, J. Hamada, M. D. Yamanaka, and F. Kimura, 2009: Why a large amount of rain falls over the sea in the vicinity of western Sumatra Island during nighttime. J. Appl. Meteor. Climatol., 48, 1345-1361.

Yang, S., and E. A. Smith, 2006: Mechanisms for diurnal variability of global tropical rainfall observed from TRMM. J. Climate, 19, 5190-5226.

Yang, G. Y., and J. Slingo, 2001: The diurnal cycle in the tropics. Mon. Wea. Rev., 129, 784-801.

Zangl, G., 2012: Extending the numerical stability limit of terrain-following coordinate models over steep slopes. Mon. Wea. Rev., 140, 3722-3733.

Zhou, L., and Y. Wang, 2006: Tropical Rainfall Measuring Mission observation and regional model study of precipitation diurnal cycle in the New Guinean region. J. Geophys. Res., 111, D17104, doi:10.1029/2006JD007243. 